Results Providers overwhelmingly focused on parental beliefs as barriers to HPV vaccination, though noted other factors including the lack of school requirements and barriers related to serving a lowincome, immigrant clientele. Perceived parental misconceptions acting as barriers included the belief that adolescents do not need vaccinations and that no-cost vaccine programs like Vaccines for Children are only available for younger children. Perceived parental concerns that the vaccine will promote sexual activity were prevalent, especially for parents of 11-12-year-old girls, which prompted providers to frame HPV vaccine as a "routine," "cervical cancer" vaccine. However, providers felt mothers with experience with abnormal Pap tests and those with a supportive friend or relative were more likely to request HPV vaccine. Providers noted that for Hispanic parents the "preferred" source of information is peers; if the "right people" in the community were supportive of HPV vaccine, parents were more willing to vaccinate. Most providers noted that because HPV vaccine is not "required" for school, it was difficult to get eligible girls into clinic and to reinforce to parents the need for the vaccine. Other barriers included lack of immunisation records among immigrant parents and a difficult-to-reach, mobile clientele.

Conclusions Providers noted a number of barriers to HPV vaccination, including some perceived parental misconceptions that could be addressed with education about the need for adolescent vaccines and available free vaccine programs. Because community support appears particularly important to Hispanic parents, the use of promotoras - peer liaisons between health organisations and the community-may increase HPV vaccine uptake in this population. Future research should explore how well providers' perceptions align with parents' actual concerns.

\section{P5-S6.15 SOCIAL WORK SERVICES AT NEW YORK CITY HEALTH DEPARTMENT STD CLINICS}

doi:10.1136/sextrans-2011-050108.571

T Ciprian, A Lifflander, S Sobin, M Kosovrasti, A Muzacz. New York City Department of Health and Mental Hygiene, New York, New York, USA

Objective To describe the introduction of social work services in New York City Department of Health \& Mental Hygiene Bureau of STD Control (NYC DOH) clinics.

Background Each year the NYC DOH STD clinics serve over 120000 patients. Services include free and confidential testing for HIV and other STDs, STD treatment, emergency contraception and the hepatitis vaccine. Social work services were introduced at the STD clinics in 2008 to address mental health and social service needs that often drive high risk sexual behaviour, such as substance abuse, domestic violence and untreated mental illness. Social work services include short-term counselling and referrals to outside agencies.

Methods Patients are routinely screened for social work and mental health needs during interviews with physicians or disease intervention specialists (DIS), and are referred to a social worker or mental health counsellor assigned to the clinic. As appropriate, patients are provided with behavioural interventions utilising motivational interviewing techniques and short term counselling. Patients are also referred to local resources for additional services.

Results Since July 2009, 471 patients were referred to the on-site social worker or mental health counsellor and 460 (97\%) were evaluated. 40/460 patients ( $9 \%$ ) received short-term counselling at a NYC DOH STD clinic. 200/460 patients (43\%) were referred to local agencies specialising in domestic violence/sexual assault, public health benefits/health insurance to legal and housing services. 100/ 460 patients $(22 \%)$ were referred to a health clinic and $120 / 460$ (26\%) patients were connected to mental health agencies. All 40 patients who received short term counselling at a DOH STD clinic returned for follow-up social work visits, independent of STD care.
Conclusion In a busy STD clinic, social work services can be introduced and utilised by patients, allowing physicians and DIS to focus on clinical patient issues. Offering more comprehensive care may be expected to improve patient outcomes and care. Follow-up data are required to measure the long-term impact of these services on sexual risk-taking and on rates of STDs and HIV.

\section{P5-S6.16 NOVEL MODULAR TEACHING OF HIV PATIENTS IN RESOURCE-LIMITING SETTING: EFFECT OF LEARNING OUTCOMES ON ADHERENCE TO HIGHLY ACTIVE ANTIRETROVIRAL THERAPY (HAART)}

doi:10.1136/sextrans-2011-050108.572

${ }^{1} 0$ Busari, ${ }^{1} 0$ Busari, ${ }^{2} \mathrm{~A}$ Adeyemi, ${ }^{3} \mathrm{M}$ Nakayima. ${ }^{1}$ Federal Medical Centre, Ido-Ekiti, Nigeria; ${ }^{2}$ Family Health International, Abuja, Nigeria; ${ }^{3}$ The AIDS Support Organization, Masaka, Uganda

Background Patient education is a crucial aspect of antiretroviral treatment of HIV patients and plays a significant role in adherence to HAART, development of OIs, hospitalisation and mortality. Unfortunately, in most resource-poor setting, this is not often done, and when it is done, often casually.

Objective Objective was to compare a modular teaching method (MTM) with traditional patient education (TTM), and evaluate its effectiveness on adherence to HAART, development of OIs, hospitalisation and mortality.

Methods $420 \mathrm{HIV}$-positive patients on HAART, zidovudine, lamivudine and nevirapine, were recruited and randomly divided into subject and control groups. A pre-test and post-test time-series design was used to collect data using a 30-item knowledge and skills assessment schedule with items rated on a 5-point Linkert-type scale. The schedule was pre-tested on 50 patients with Cronbach's Score of 0.92 and a test-retest co-efficient of 0.89 at a 4 -week interval. The MTM consist of 10 modules which address issues on adherence such as benefits of treatment, family and social support, adverse drug effects, psychological factors, substance abuse, patientprovider relationship, patient's self efficacy and effect of traditional/ cultural values. MTM was used to educate subject group while the controls received the traditional teaching by nurses on the wards. Teaching was done throughout the period of hospitalisation. All the patients were followed for 8 months at 4-week intervals via outpatient clinic and home visits. $\chi^{2}$ and t-tests were used; $p<0.05$ was considered significant.

Results Mean age was $28.7 \pm 6.9$ years. Mean adherence rate for the subjects was $98.9 \pm 1.0 \%$ and for controls, $87.6 \pm 2.4 \%(p<0.001)$. Frequency of OIs per patient per month was lower in subjects than in controls ( 0.51 vs $1.31, p=0.002)$. Mean number of readmissions per patient per month during the 8-month follow-up was $0.18 \pm 0.01$ for subjects and $0.89 \pm 0.02$ for controls $(p=0.0012)$. Subject group had shorter hospital stay ( $6.2 \pm 2.6$ days vs $15.7 \pm 4.8$ days, $\mathrm{p}=0.002)$ and lower mortality $(p=0.008)$ than the controls.

Conclusion MTM has significant effect on adherence to HAART, development of OIs, readmission rate, hospital stay and mortality. MTM is recommended as a core aspect of adherence counselling and antiretroviral treatment programme.

\section{P5-S6.17 FACILITATING ACCESS TO SEXUAL HEALTH SERVICES FOR MEN WHO HAVE SEX WITH MEN (MSM) AND TRANSGENDER PERSONS IN GUATEMALA CITY}

doi:10.1136/sextrans-2011-050108.573

${ }^{1} \mathrm{~S}$ Boyce, ${ }^{2} \mathrm{C}$ Barrington, ${ }^{3} \mathrm{~J}$ Herbert Bolanos, ${ }^{4} \mathrm{C}$ Galindo Arandi, ${ }^{5} \mathrm{G}$ Paz-Bailey. ${ }^{1}$ Tephinet Inc., Atlanta, USA; ${ }^{2}$ University of North Carolina, Chapel Hill, USA; ${ }^{3}$ Universidad San Carlos, Guatemala City, Guatemala; ${ }^{4}$ Del Valle University of 